[0212-7199 (2005) 22: 2; pp 53-54] ANALES DE MEDICINA INTERNA Copyright (C) 2005 ARAN EDICIONES, S.L.

An. MED. InTERna (Madrid) Vol. 22, N. $^{\circ} 2$, pp. $53-54,2005$

\title{
Probióticos: ¿fantasía o realidad?
}

Martínez-Cócera C, Mesa del Castillo Payá M. Probióticos: ¿fantasía o realidad? An Med Interna (Madrid) 2005; 22: 53-54.

Los probióticos están de moda, la industria alimentaria prodiga a diestro y siniestro las bondades de los alimentos suplementados con microflora intestinal, parecen que mejoran muchas patologías y previenen otras tantas. Como todo lo que se publicita con tanta seguridad suscita dudas. ¿Qué son los probióticos?, ¿para qué sirven?, ¿es prudente ingerir bacterias, cuando llevamos toda la vida utilizando antibióticos cada vez más eficaces para erradicarlas?

Es muy difícil dar una visión precisa de la microbiota intestinal "normal"; por una parte existen variaciones cualitativas y cuantitativas de una persona a otra, ligadas al propio individuo, a su raza, a su alimentación y por otra se desconoce gran parte de la microbiota del tracto intestinal superior debido a su inaccesibilidad y a la necesidad de técnicas invasivas para su estudio. Las heces son las muestras más estudiadas, pero son un reflejo imperfecto de lo que ocurre realmente a nivel del ecosistema microbiano digestivo, en ellas es difícil distinguir entre microorganismos indígenas y colonizadores transitorios, ingeridos por alimentos o arrastrados de hábitats próximos.

La microflora intestinal en el hombre es del orden de $10^{14}$ bacterias constituidas por unas 500 especies diferentes. En el momento del nacimiento, la cavidad oral y el tracto digestivo son rápidamente colonizados por una micobiota muy diversa, llegando a alcanzar desde las 48 horas de vida tasas de $10^{9}$ a $10^{11}$ bacterias por gramo de heces, tasas que son próximas a las del adulto, sin embargo esta microbiota es menos compleja, existiendo variaciones cualitativas entre los niños que reciben lactancia materna o artificial.

Entre las funciones de la microbiota intestinal normal se encuentran: el establecimiento de una arquitectura normal de las vellosidades, diversos efectos metabólicos y nutricionales (produción de nutrientes y vitaminas), capacidad para metabolizar un gran número de compuestos exógenos y endógenos destacando los Lactobacillus que desempeñan un papel clave en la biotrasformación de los esteroides, incrementan las células productoras de $\operatorname{Ig} \mathrm{A}$, poseen efecto de protección contra infecciones y colonización bacteriana patógena.

El equilibrio que existe a nivel del ecosistema intestinal está en perpetua evolución, es un equilibrio dinámico que puede ser roto bajo la influencia de numerosos factores ambientales, anatómicos y funcionales y sobre todo la toma de antibióticos tiene el riesgo de provocar localmente profundas perturbaciones en la microbiota autóctona.

La adicción de cierto tipo de bacterias contribuye al mantenimiento de un determinado tipo de flora; con esta base nace el concepto de probiótico: "Microorganismo vivo, componente de los alimentos que cuando se ingiere tiene un efecto beneficioso sobre el individuo mejorando el equilibrio de su flora intestinal". Dado que la adicción de bacterias vivas a los alimentos tiene problemas tecnológicos han surgido los prebióticos que son componentes no digeribles de un alimento que al ingerirse promueven el crecimiento y establecimiento de gérmenes beneficiosos de la flora intestinal. El mejor ejemplo de prebiótico es la leche materna. La presencia de probióticos y prebióticos en un mismo alimento constituyen los simbióticos. Las especies bacterianas utilizadas son: los Lactobacillus (Acidophilus, Casei-Rhamonusen-GG, Bulgaricus), Bifidobacteria (Bifidum, longun, breve, infantum, animalis), Strectoccocus thermophilus y Saccharomyces boulardii.

Han sido utilizadas en numerosas patologías, en unas se ha demostrado su efecto beneficioso y en otras solo se ha sugerido. Una de las indicaciones demostradas es el tratamiento y prevención de las diarreas, numerosos estudios demuestran que disminuye la gravedad y la duración de la diarrea de origen vírico y que es eficaz en el tratamiento de las recaídas por Clostridium difficile. Otras líneas de trabajo es el uso de los probióticos para disminuir el colesterol y para prevenir la carcinogénesis.

En cuanto a la patología alérgica, hace años se demostró que los niños que presentaban menos flora intestinal, por uso de antibióticos, lactancia artificial, el uso de una higiene desproporcionada, etc., presentaban más patología alérgica que los niños en los que no se daban estos factores. De estos estudios surgió la teoría de la higiene que viene a explicar que el reciente incremento de las enfermedades alérgicas se debería a un desequilibrio inmunológico entre la inmunidad mediada por citoquinas Th1 y Th2. Seria lógico pensar que el tratamiento con probióticos, que estimularían la inmunidad Th1, ayudara de alguna manera a prevenir la sensibilización alérgi- 
ca a antígenos alimentarios en el ámbito intestinal. Sin embargo es muy difícil demostrar mediante estudios controlados las bondades de estas bacterias ya que, como hemos comentado anteriormente, existen más de 500 especies diferentes de microbiota intestinal, muchas de ellas desconocidas, y poder afirmar el efecto beneficioso "in situ” supondría realizar técnicas muy invasivas en sujetos sanos y un análisis microbiológico detallado. Recientemente se han publicado estudios que evalúan mediante scores de sintomatología, pruebas cutáneas e incluso algunos con mediciones de interleuquinas del perfil Th1 o Th2 en sangre periférica, el efecto beneficioso de los probióticos en grupos de niños alérgicos a proteínas de leche de vaca y dermatitis atópica, concluyendo que existe un efecto beneficioso en la prevención de la sensibilización a proteínas de leche de vaca y mejoría de la sintomatología de la dermatitis atópica, mientras que otros autores solo muestran un ascenso significativo de INF- $\gamma$ (principal citoquina Th1) en sangre periférica, sin repercusión en la clínica. Incluso existen dos estudios en la bibliografía que afirman el efecto beneficioso de las cepas de Lactobacillus en la sintomatología de la rinitis alérgica perenne. En cualquier caso hay que ser cauto con estos resultados ya que se necesitan estudios con cepas bien definidas microbiológicamente, siendo improbable que una solo especie bacteriana probiótica tenga la capacidad para influir sobre la ecología microbiana del huésped.

Solo se ha demostrado de forma eficaz el uso de probióticos en las diarreas víricas y por Clostridium difficile y el efecto terapéutico y preventivo en otros procesos necesitan mas estudios que lo demuestren claramente. Queda pendiente establecer la especifidad de cada probiótico, para qué proceso es más adecuado cada uno, la forma de administración que asegure la viabilidad de estos gérmenes, las dosis y pautas de tratamiento.

Actualmente no existe normativa que regule la fabricación de estos productos, de forma que muchos alimentos etiquetados como bioalimentos no contienen ni el número ni el tipo de microorganismos que afirman, por lo tanto y ante la avalancha publicitaria de este tipo de productos, es necesario establecer unos criterios que los regulen para así evitar fraudes.

\section{MARTÍNEZ-CÓCERA, M. MESA DEL CASTILLO PAYÁ}

Servicio de Alergología. Hospital Universitario San Carlos. Madrid

\section{Bibliografía}

1. Biller JA, Katz AJ, Flores AF, Buie TM, Gorbach SL. Treatment of recurrent Clostridium difficile colitis with lactobacillus GG. J Pediatr Gastroenterol Nutr 1995; 21: 224-226.

2. De Luis DA, Santamaría AR, González Sagrado M, Izaola O, Armentía A, Aller R. Estudio de la influencia del consumo de lácteos fermentados en una población de pacientes alérgicos. An Med Interna (Madrid) 2005; 22: 55-58.

3. Helin T, Haahtela S, Haahtela T. No effect of oral treatment with an intestinal bacterial strain, Lactobacillus rhamnosus (ATCC 53103), on birch-pollen allergy: a placebo-controlled double-blind study. Allergy 2002; 57: 243-6.

4. IsolauriE, Ribeiro Had C, Gibson G, saavedra J, Saliminen S, Vanderhoof J, Varavithya W. Functional foods and probiotics: Working group report of the first world congress of pediatric gastroenterology, hepatology and nutrition. J Pediatr Gastroenterol Nutr 2002; 35 (Supl. 2): S106-109.

5. Kalliomaki M, Salminen S, Poussa T, Arvilommi H, Isolauri E. Probio- tics and prevention of atopic disease: 4-year follow-up of a randomised placebo-controlled trial. Lancet 2003; 361 (9372): 1869-71.

6. Nappert G, Barrios JM, Zello GA, Naylor JM. Oral rehidratation solution therapy in the management of children with rotavirus diarrhea. Nutr Rev 2000; 58: 80-87.

7. Niers LE, Rijkers G, Knol EF, Meijer Y, Hoekstra MO. Probiotics for prevention of atopic disease? Lancet 2003; 362 (9382): 496.

8. Rosenfeldt V, Benfeldt E, Nielsen SD, Michaelsen KF, Jeppesen DL, Valerius NH, Paerregaard A. Effect of probiotic Lactobacillus strains in children with atopic dermatitis. J Allergy Clin Immunol 2003; 111 (2): 389-95.

9. Vanderhoof JA, Young RJ. Role of probiotics in the management of patients with food allergy. Ann Allergy Asthma Immunol 2003; 90 (6 Supl. 3): 99-103.

10. Zacconi C, Bottazzi V, Tebechi A, Bosi E, Sarra PG, Tagliaferri L. Serum cholesterol levels in exenic mice colonized with Enterococcus faecium and Lactobacillus acidophilus. Microbiología 1992; 15: 413-417. 